\title{
Environment and health: Risk perception and its determinants among Italian university students
}

\author{
Annalaura Carducci ${ }^{a}$, Maria Fiore ${ }^{b}$, Antonio Azara ${ }^{c}$, Guglielmo Bonaccorsi ${ }^{\text {d }}$, Martina Bortoletto ${ }^{\mathrm{e}}$, \\ Giuseppina Caggiano ${ }^{\mathrm{f}}$, Andrea Calamusa ${ }^{\mathrm{a}}$, Antonella De Donno ${ }^{\mathrm{g}}$, Osvalda De Giglio ${ }^{\mathrm{f}}$, Marco Dettori ${ }^{\mathrm{c}}$, \\ Pamela Di Giovanni ${ }^{\mathrm{h}}$, Angela Di Pietro ${ }^{\mathrm{i}}$, Alessio Facciolà ${ }^{\mathrm{j}}$, Ileana Federigi ${ }^{\mathrm{a}, ~}$, , Iolanda Grappasonni ${ }^{\mathrm{k}}$,
} Alberto Izzotti ${ }^{1}$, Giovanni Libralato ${ }^{\mathrm{m}}$, Chiara Lorini ${ }^{\mathrm{d}}$, Maria Teresa Montagna ${ }^{\mathrm{f}}$, Liberata Keti Nicolosi ${ }^{\mathrm{n}}$, Grazia Paladino ${ }^{\mathrm{n}}$, Giacomo Palomba ${ }^{\mathrm{a}}$, Fabio Petrelli ${ }^{\mathrm{k}}$, Tiziana Schilirò ${ }^{\circ}$, Stefania Scuri ${ }^{\mathrm{k}}$, Francesca Serio ${ }^{\mathrm{g}}$, Marina Tesauro $^{\mathrm{p}}$, Marco Verani ${ }^{\mathrm{a}}$, Marco Vinceti ${ }^{\mathrm{q}}$, Federica Violi ${ }^{\mathrm{q}, \mathrm{r}}$, Margherita Ferrante ${ }^{\mathrm{b}}$

${ }^{a}$ Department of Biology, University of Pisa, Pisa, Italy

b Department of Medical, Surgical Sciences and Advanced Technologies “G. F. Ingrassia”, Catania University, Catania, Italy

${ }^{c}$ Department of Medical, Surgical and Experimental Sciences, University of Sassari, Sassari, Italy

d Department of Health Science, University of Florence, Florence, Italy

e Azienda ULSS 2 Marca Trevigiana - Treviso District, Workers' Preventive Medicine Service, Treviso, Italy

${ }^{\mathrm{f}}$ Department of Biomedical Sciences and Human Oncology, University of Bari “Aldo Moro”, Bari, Italy

${ }^{g}$ Laboratory of Hygiene, Department of Biological and Environmental Sciences and Technology, University of Salento, Lecce, Italy

h Department of Pharmacy, "G. d'Annunzio" University of Chieti-Pescara, Chieti, Italy

i Department of Biomedical and Dental Sciences and Morphofunctional Imaging, University of Messina, Italy

${ }^{\mathrm{j}}$ Department of Clinical and Experimental Medicine, Unit of Infectious Diseases, University of Messina, Italy

${ }^{\mathrm{k}}$ University of Camerino, School of Medicinal and Health Products Sciences, Camerino, Italy

${ }^{1}$ Department of Health Sciences, University of Genoa, Genoa, Italy

${ }^{\mathrm{m}}$ Department of Biology, University of Naples Federico II, Naples, Italy

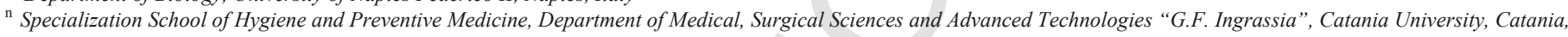
Italy

${ }^{\circ}$ Department of Public Health and Pediatrics, University of Torino, Torino, Italy

${ }^{\mathrm{p}}$ Department of Biomedical, Surgical and Dental Sciences, University of Milan, Italy

${ }^{\mathrm{q}}$ Section of Public Health, Department of Biomedical, Metabolic and Neural Sciences, University of Modena and Reggio Emilia, Modena, Italy

${ }^{\mathrm{r}}$ Clinical and Experimental Medicine PhD Program, University of Modena and Reggio Emilia, Modena, Italy

\section{A R T I C L E IN F O}

Article history:

Received 22 May 2019

Received in revised form 12 July 2019

Accepted 13 July 2019

Available online $\mathrm{xxx}$

Editor: Damia Barcelo

Keywords

Environmental health risk perception

Students

Public health

Functional health literacy

Risk communication

\section{A B S T R A C T}

Among the determinants of environmental health risk perception, health literacy and social media messages have been generally neglected. This study details the environmental health risk perception and its determinants in Italian university students, including a measure of functional health literacy and an analysis of newspapers and social media. A cross sectional survey was carried out among students from 15 Italian universities and different disciplines (grouped into Scientific-Health and Humanistic-Legal-Social sectors) using a self-administered anonymous questionnaire, divided into six sections: socio-demographic characteristics, information on health and environment, environmental health risk perception, trust, attitudes and behaviors and functional health literacy. Local newspapers and tweets in the same areas and period were analyzed in relation to quantity and topics. The study population included 4778 students ( $65.1 \%$ female) aged $21 \pm 4.3$ years, and functional health literacy was low (below the cutoff value) for $44.4 \%$ of students

A new outcome of the survey is that the detected association between high functional health literacy a higher global health risk perception and trust in institutions both as sources of information and as actors for protection against environmental risks.

The internet and social networks were the most frequently consulted sources of information $(77.7 \%)$, which was predictive of a higher risk perception. The possible relation between environmental health risk perception and tweet communication was highlighted by a comparison between the risk perception in the city with the highest number of tweets (Modena) and another one similar for socio-demographic characteristics (Pisa). In conclusion, the results of our study may be of help to strengthen information and education

* Corresponding author at: Department of Biology, University of Pisa, Via S. Zeno 35/

39, Pisa 56127, Italy.

Email address: ileana.federigi@biologia.unipi.it (I. Federigi) 
programs: functional health literacy should be taken into account in school programs, to produce a basic knowledge for a better understanding of health and environment. Moreover, mass and social media should be included in planning communication intervention and in verifying their results.

\section{Introduction}

Risk communication is defined by WHO as an essential component of the risk analysis, strictly linked to the other two components of risk assessment and management, at the basis of public health prevention strategies (WHO, 2013; Covello and Allen, 1998). The environmental risk communication from public health institutions should be carefully programmed and based on an accurate study of the context (Covello, 2003; Smillie and Blissett, 2010), including the assessment of public risk perception and trust as well as their determinants.

According to the studies on environmental health risk perception (Sandman, 2003), it includes a combination of "hazard" (the risk evaluated by experts: probability times severity of harm) and "outrage" (a global emotional experience of fear, anger and concern, causing a feeling of injustice).

Various determinants of the outrage have been identified, including: voluntariness, control, fairness, process, morality, familiarity, memorability, dread, diffusion in time and space (Sandman, 1987, 2003). They mainly pertain to the nature of risk and the ways it is managed by institutions; however, an important role could also be attributed to people's attitudes, trust and awareness and the media influence.

Health literacy and mass media/social media information are rarely considered in studies and guidelines (Kuroda et al., 2018), despite their proven representativeness of risk perception, awareness and behaviors in many contexts (Institute of Medicine, 2004; Bennett et al., 2010; Berkman et al., 2011; Kickbusch et al., 2013).

Health literacy was initially defined as "the capacity to obtain, process and understand basic health information and services needed to make appropriate health decisions" (Ratzan and Parker, 2000; Institute of Medicine, 2004). It has subsequently been given a more complex definition, differentiating between functional, communicative and critical health literacy (Nutbeam, 2000, 2008), where functional health literacy represents the baseline individual literacy skills needed to read and understand health information.

The growing complexity of health-related information scenarios has led to further distinctions, defining e-health literacy (Kayser et al., 2018) and health literacy related to specific topics such as vaccine health literacy (Lorini et al., 2018) or environmental health literacy (Finn and O'Fallon, 2017). In studies where measurements of health literacy have been included in surveys on attitudes and perceptions, they were found to be strongly related to knowledge, health behaviors, health outcomes and medical costs (Institute of Medicine, 2004; Berkman et al., 2011; Kickbusch et al., 2013). On the other hand, few studies have investigated the relationships between health literacy and risk perception of environmental issues (Kuroda et al., 2018).

Mass media have a significant influence both on the knowledge and attitudes of people (Nelkin, 1987), as well as risk perception (Bennett et al., 2010). Studying mass media information is a useful mean to understand social "sentiments" and tendencies in political debates (Scheufele, 2014). In addition, it has also been used to estimate the public risk perceptions regarding health-related topics, such as epidemics (Dettori et al., 2018), vaccines (Aquino et al., 2017) or environmental risks (Carducci et al., 2017; Dettori et al., 2019).

The aim of the present study was to give a broad picture of the environmental health risk perception and its determinants in university students in Italy, by analyzing 15 universities and students from different disciplines.

In response to the lack of information on the relations of health literacy and mass media/social media messages with environmental health risk perceptions as well as the lack of tools to investigate them, our study included factors such as functional health literacy, mass media and social media coverage.

Another specific objective was to propose a functional health literacy measure that would be easily applicable in environmental risks perception surveys. This is represented by a simple test, which it has been already used in previous studies for other topics and populations (Calamusa et al., 2012) and it is easily translatable in other languages and contexts.

\section{Methods}

\subsection{Study population and data collection}

From November 2017 to January 2018 we conducted a survey among students attending courses in 15 Italian Universities: Bari, Camerino, Catania, Chieti, Florence, Genoa, Lecce, Messina, Milan, Modena, Naples, Padua, Pisa, Sassari, and Turin (Fig. 1). Students were distributed in the sectors of Scientific-Health (biological and environmental sciences, biotechnology, medicine, pharmacy, physics, mathematics, civil and industrial engineering) and Humanistic-Legal-Social (sociology, political sciences, communication sciences, literature, philosophy, cultural heritage, business economics, economics and finance, law).

The survey instrument was a questionnaire, distributed by researchers in classrooms or study rooms, autonomously compiled by the students in the same places and collected immediately after compilation in boxes to guarantee the anonymity. This modality configures the study as cross-sectional, and the measurements of risk perception as prevalence in a population which represents future adult leaders in scientific as well as humanistic sectors. Before the distribution, researchers explained to the participants how filling out the self-administered questionnaire, informed consent was being given for the use of data for research purposes, according to the Law for Protection of Personal Data and the European Code of Conduct for Research Integrity (at www.allea.org), established by the ALLEA (All European Academics). The questionnaire and the study protocol were approved by the Ethical Committee of the University of Milan.

The questionnaire was tested, adjusted and validated through a pilot study, carried out on a convenience sample of 362 students in seven universities (Bari, Catania, Chieti, Messina, Modena, Pisa, Sassari).

The internal consistency of the Risk Perception Index sections was assessed with Cronbach's alpha test.

The final questionnaire (available in the Supplemental Material A) consisted of 21 close-ended questions and was divided into six sections:

1) Socio-demographic characteristics: gender, age, area of residence and the sector of university degree course attended (Scientific-Health or Humanistic-Legal-Social);

2) Information: 1. Sources. 2. Trust in these sources. 3. Perceived quality of information. 4. Self-evaluation of knowledge on envi- 


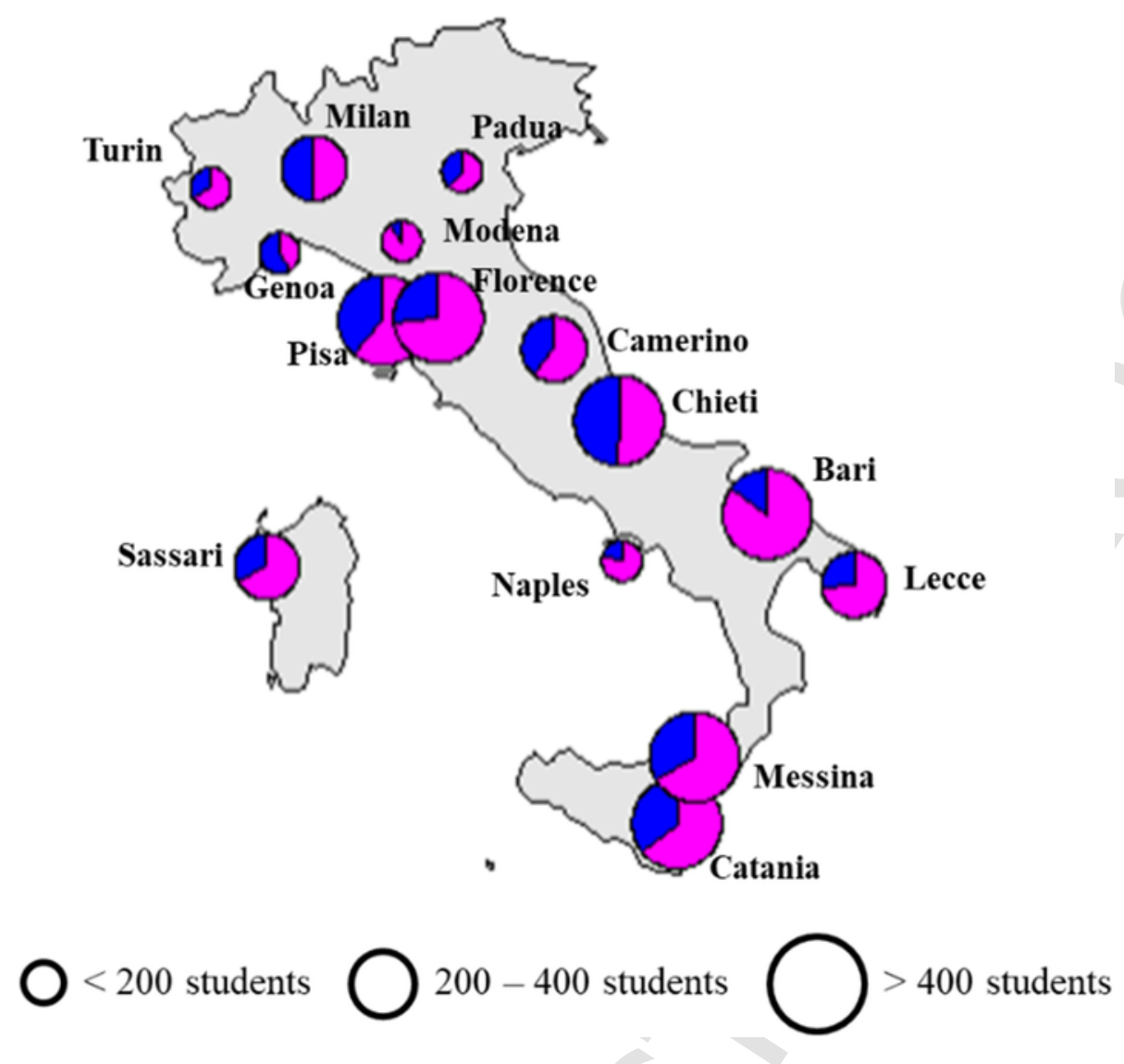

Fig. 1. Location of the universities involved, gender distribution and sample size.

ronmental health risks. The trust was measured by a Likert 4-point-scale ( 1 =none, 2 = little, $3=$ limited, $4=$ a lot $)$;

3) Environmental health risk perception was explored through five questions: 1. Estimation of burden of environmental diseases. 2. Opinion on the association between environmental factors and some diseases (6 items). 3. Risk perception regarding environmental risks (25 items). They were chosen to provide a list as wide as possible of the issues of concern for the population. 4. Risk perception of behavioral risks (5 items). 5. General environmental health risk perception and self-perception of their own health status (6 items). 6. Smoking habits, to find relations with environmental risk perception. Except for questions 1 and 6 , the answers were coded according to a Likert 5 -point-scale $(1=$ not important, $2=$ not very important, $3=$ quite important, $4=$ very important, 5 =extremely important). For question in point 3, a "global risk perception index" was calculated summing the scores given to the single items (maximum $=125$ ). For question in point 5 , scores were summed to calculate a "general risk perception index";

4) Trust in different subjects: 1. Evaluation of the importance for pollution reduction and control (11 items: 6 institutional and 5 non-institutional subjects). 2. Evaluation of the extent to which these subjects fulfill pollution reduction and control. The answers were coded according to a Likert 5-point-scale $(1=$ scarce, $2=$ sufficient, $3=$ medium, $4=$ high, $5=$ very high). Global indexes of trust (for institutional and non-institutional subjects) were calculated by the sum of scores for the corresponding items;

5) Attitudes and behaviors in reducing and controlling environmental pollution (five questions): the answers to this section were not considered in the present paper and will be the topic of a further publication;

6) Functional health literacy: to measure the ability to read and understand information related to health, a tool previously designed was used (Calamusa et al., 2012) in order to include this factor in KPAB (Knowledge Perceptions Attitudes and Behaviors) questionnaires on different themes. Briefly, the understanding of 12 terms (chosen from a list of the most common words obtained through a computational linguistic analysis of a sample of information leaflets of the 38 bestselling over-the-counter medicines) was tested by asking participants to place them in the correct section of a stylized body divided into four sections.

\subsection{Newspapers and social media analysis}

A search of articles published by local newspapers of the participating cities in the days immediately preceding and during the survey period (specific for each city) was carried out with three keywords (pollution, air pollution and smog). The articles were then examined by two independent reviewers in relation to the pertinence, topic and tone of the message. The tones of the messages were classified either as alarming or not alarming.

For the same periods, tweets with the same keywords were downloaded with NCapture (QSR C International Pty Ltd. NCapture Help.) and reviewed in terms of pertinence and topic and tone. 


\subsection{Data analysis}

The answers to the questionnaire were coded as qualitative data or scores, according to the question, and analyzed with SPSS 21.0 software (SPSS Inc., Chicago, IL, USA).

The frequency of answers was compared with the chi-squared test and Cramers' V. For the Likert scales, the medians were calculated. For some questions (i.e. trust in sources of information, risk perception and trust in subjects for pollution control) a global score was calculated summing the single items. Global trust indexes were calculated separately for the institutional subjects (Ministries of Health and Environment, Public Health and Regional Environmental Agencies, Municipalities, Regions and Physicians) and for the non-institutional subjects ("ecolabel" industries, environmentalist associations, non-governmental organizations, local community stakeholders, and individual citizens).

For the functional health literacy, each answer was coded as 1 (correct) or 0 (missing or incorrect), and a total functional health literacy score was calculated (minimum 0 , maximum 12). The total score was divided into two levels: $\leq 9$ (low functional health literacy) and $>9$ (high functional health literacy) based on its median value (Calamusa et al., 2012).

A bivariate analysis was performed using Student's $t$-test or Mann-Whitney $U$ test, as appropriate, whereas the multiple group comparisons were carried out with analysis of variance (ANOVA) or Kruskall-Wallis test.

A multiple logistic analysis was performed to find the determinants of risk perception and trust. The following variables were thus dichotomized (taking the median as the cutoff value): risk perception index (low $\leq 75$, high $\geq 75$ ) and trust in institutional subjects (low $\leq 21$, high $\geq 21$ ) and in non-institutional subjects (low $\leq 15$ high $\geq 15$ ) as dependent variables, the internet and social media as sources of information (yes or no), functional health literacy (low $=\leq 9$, high $\geq 9$ ), gender, area of residence (centre-north and south-islands) and smoking habits as independent variables.

In order to evaluate the impact of newspapers and twitter information on risk perception, the correlation between the number of alarming articles and risk perception index for cities was investigated and the same was done for tweets. In the case of cites showing a peak of Twitter or newspapers articles, a more extensive analysis was planned to compare risk perception, globally and for a single risk factor.

The results obtained revealed a peak in Modena: the data from this city were compared with those from Pisa, which in turn shows a high number of tweets and is similar to Modena with regard to demographic characteristics (ISTAT, 2018).

All the statistical tests were two-sided and $p$-values were calculated to show the level of differences/associations. The most recent epidemiological tendencies suggest not to use $\mathrm{p}$ statistics to define significance because there is an intrinsic risk of misinterpreting the data, i.e. to give importance to information that have not and, vice versa, to neglect important data (Rothman et al., 2008; Wasserstein and Lazar, 2016). Nevertheless, we decided to highlight (with asterisks in the tables) the most relevant differences/associations in order to facilitate data interpretation.

\section{Results}

\subsection{Internal consistency of the questionnaire and response rate}

Cronbach's alpha reliability test showed a global value of 0.905 , which highlights the very good internal consistency of the global risk perception index (25 items, values from 25 to 125 ).

Because the questionnaire was distributed and completed during lessons or study hours, the response rate was very high (over 99\%). The main explanation reported for the non-respondents was a lack of time due to exam preparations.

\subsection{Study population: Socio-demographic characteristics and health literacy}

The study population included 4778 students $(65.1 \%$ female) aged $21 \pm 4.3$ years. A total of 2505 participants $(53.2 \%)$ belonged to the scientific-health sector. Overall, $65.1 \%$ of students were following three-year degree courses (bachelor's degree). The mean functional health literacy level was $10 \pm 3$ : functional health literacy was $\leq 9$ for $44.4 \%$ of students and $>9$ for $55.6 \%$. The most represented area of residence was southern Italy, including Sicily and Sardinia which accounted for $57.1 \%$ of respondents, followed by the centre $(25.0 \%)$ and the north $(17.9 \%)$. Among the socio-demographic variables, functional health literacy was lower for people following three-year degree courses, and for the scientific health-sectors (Fig. 2).

A minor difference was found among areas of residence, with the highest percentage of functional health literacy $>9$ in the centre, followed by the south-islands, and finally by the north. No difference in functional health literacy was observed between genders.

\subsection{Information}

The internet and social networks were the most frequently consulted sources of information (77.7\%), followed by Newspapers and Weeklies (14.6\%), TV and Radio (7.7\%). A weak association was found between the sources of information and gender (e.g. internet and social networks: Female vs Male, 78.8\% vs 75.7\%; Newspapers and Weeklies: Female vs Male, $13.6 \%$ vs $16.5 \%$ ) and the sector (e.g. internet and social networks: Scientific-health sector vs Humanities sector, $73.7 \%$ vs $83.5 \%$ ).

Information was considered "truthful, but incomplete" by $64 \%$ of the sample; the proportion was higher among functional health literacy $>9$ students $(62.5 \%$ vs $65.2 \%)$, mainly in Milan (61.7 vs 67) and Turin (67.1 vs 79.3)

Regarding the self-evaluation of their own knowledge about environmental health risks, $29.1 \%$ of students considered it "satisfying", with the main differences due to functional health literacy $(\leq 9=25.8 \%$ vs $>9=31.7 \%$ ), above all in Catania, Chieti, Lecce, Messina and Milan, and to gender (Male $62.2 \%$ vs Female $58.4 \%$ ).

Although most students consulted the internet and social media as the main source of information (78\%), they placed "moderate" and "low" trust, respectively on these sources (internet vs social media, $48.6 \%$ vs $45.5 \%$ ) regardless of the level of functional health literacy, gender and sector; whereas students with functional health literacy $>9$ were more trusting than functional health literacy $\leq 9$ in the Ministry of Environment (40.3\% vs $37.1 \%)$, Ministry of Health (44.2\% vs $40.8 \%$ ), Regional Environmental Protection Agency $(34.3 \%$ vs $30.9 \%$ ) and University and Research Institutions (53.9\%). On the other hand, students with functional health literacy $\leq 9$ were more 


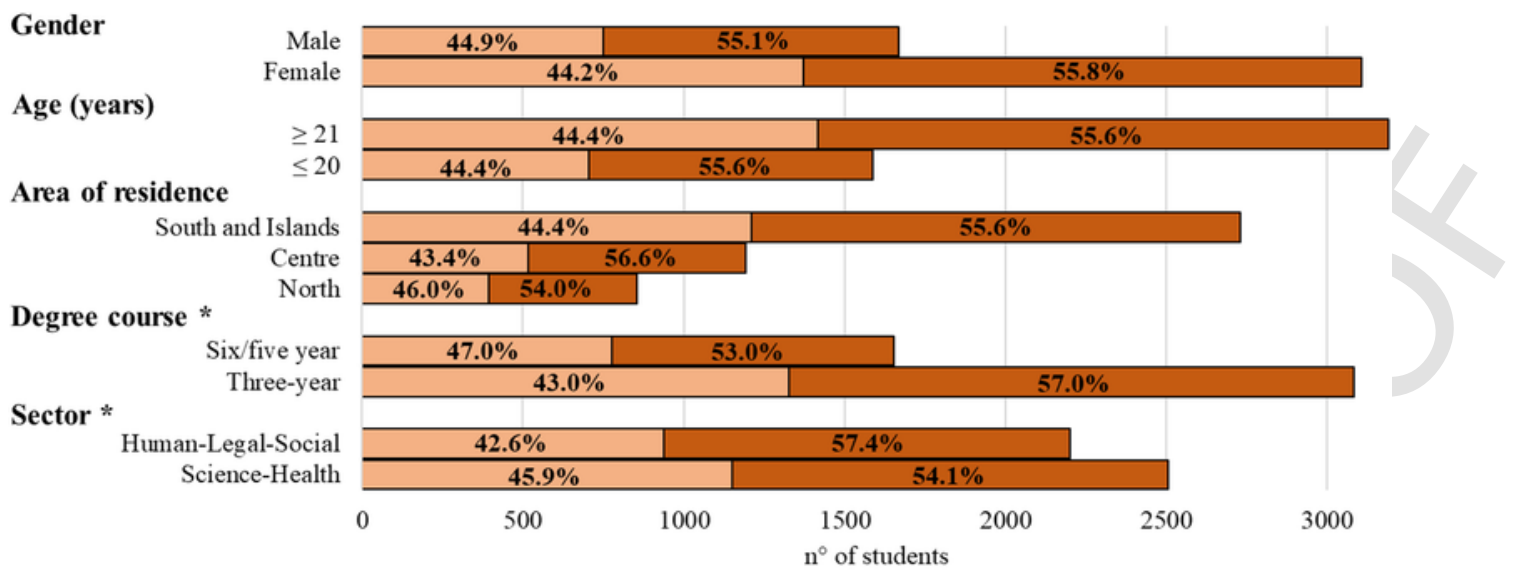

$\square$ Poor Functional Health Literacy $(\leq 9) \quad \square$ High Functional Health Literacy $(>9)$

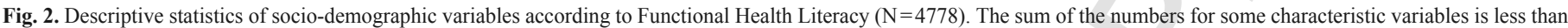
the total due to missing values. Asterix $(*)$ indicates important differences according to the bivariate analysis (Chi-square and U Mann-Whitney test).

trusting in social networks $(9.1 \%$ vs $7.5 \%)$ and experts in alternative medicines $(23.9 \%$ vs $20.5 \%)$.

The global trust index for institutional subjects as sources of information was higher for functional health literacy $>9$ (18 vs 17$)$.

No important differences in global trust in sources of information were found according to the area of residence.

During the time period of the questionnaire distribution, the number of newspaper articles varied among the different cities (Fig. 3), with a maximum in Turin (21), followed by Lecce (11), Padua and Milan (10), Sassari (8), Modena (6), Naples (5), Bari (4), Messina and Catania (3), and Pisa (2). In the remaining cities no pertinent articles were published. The most reported topics regarded air pollution ( $41.0 \%$ of articles), followed by traffic bans (14.5\%), pollution in schools $(6.0 \%)$ and other $(38.6 \%)$, and the tone was mainly negative $(78.3 \%)$.

A positive trend was detected between the number of newspapers articles and the global risk perception index, although a statistical significance was not reached, which could be attributable to the small size of the dataset (number of cities concerned).

The quantitative analysis of tweets for the same cities and periods (Fig. 4) showed a huge peak in Modena. In the figure, only cities with more than zero tweets are reported, according to social media analysis based on the defined keywords. The qualitative analysis indicated

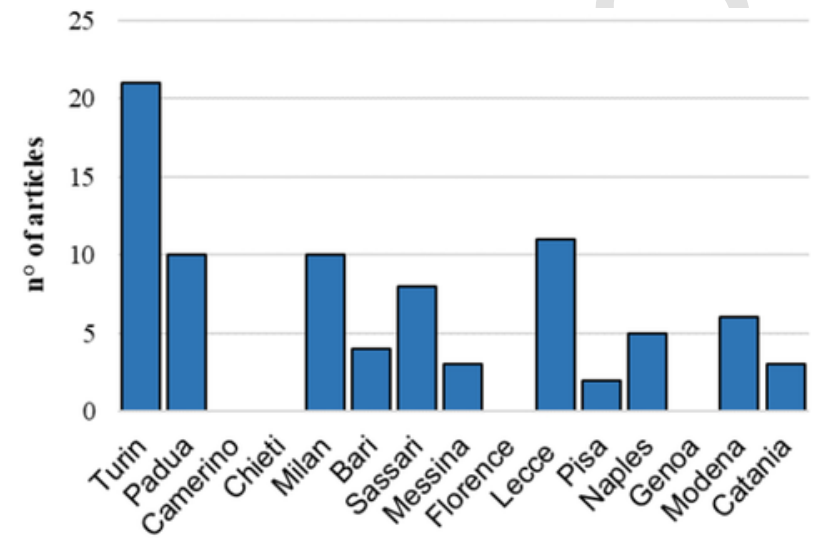

Fig. 3. Number of newspaper articles for each city in the time period of the questionnaire distribution. outdoor air quality as the most tweeted topic $(70.56 \%)$, followed by car traffic (18.45\%), exhaust and industrial emissions (2.82\%), climate change $(2.25 \%)$, chemicals in food or drinking water $(2.11 \%)$, pollution of coasts, rivers and lakes $(1.41 \%)$, indoor air quality $(1.13 \%)$, high-voltage lines, radio and TV repeaters, cellphones and pollution of groundwater $(0.42 \%)$, heating systems and thermoelectric power plants and germs in food or drinking water $(0.14 \%)$.

\subsection{Risk perception}

Only $17 \%$ of students estimated the global burden of diseases caused by environmental factors according to WHO (between 21 and $40 \%$ ), with differences between functional health literacy levels (14.4 for functional health literacy $\leq 9$ vs 16.5 for functional health literacy $>9)$. Most students overestimated this burden (82.1\%).

Respiratory diseases were considered to be mostly associated with environmental factors $(89.2 \%$ of students answered "very" or "extremely important") followed by tumors $(87.3 \%)$, infectious diseases $(77.7 \%)$, congenital malformation $(61.9 \%)$, heart diseases $(58.4 \%)$ and neurological disorders $(38.9 \%)$. No differences were found in relation to socio-demographic variables, however some differences were detected for functional health literacy in some cities: for functional health literacy $>9$ a higher proportion of students answered "very" or "extremely important" in Bari and Padua regarding tumors, in Bari and Sassari regarding infectious diseases, in Firenze, Messina, Modena and Sassari regarding congenital malformation, in Bari regarding heart diseases, and in Genoa and Sassari regarding neurological disorders.

The risk perception in relation to specific environmental risks (Fig. 5) was highest for the chemical pollution of water and food (median score 5) and the lowest for urban noise (median score 3 ). No differences were found for functional health literacy.

The perception of single risks was different among cities, above all for road accidents (perceived higher in Bari, Catania, Genoa, Lecce, Modena, Padua, Pisa, and Sassari), genetically modified food (perceived higher in Catania, Florence, Genoa, Modena, Padua, and Sassari), pollution of coasts, rivers and lakes (perceived worse in Chieti, Milan, Modena, Padua, and Turin). The highest number of perceived high risks was in Padua (7) and Genoa (9). In Naples, the perception was lower for five risks (nuclear facilities, exhausts and emissions from industries, chemicals in food or drinking water, germs in food or drinking water and traffic noise). 


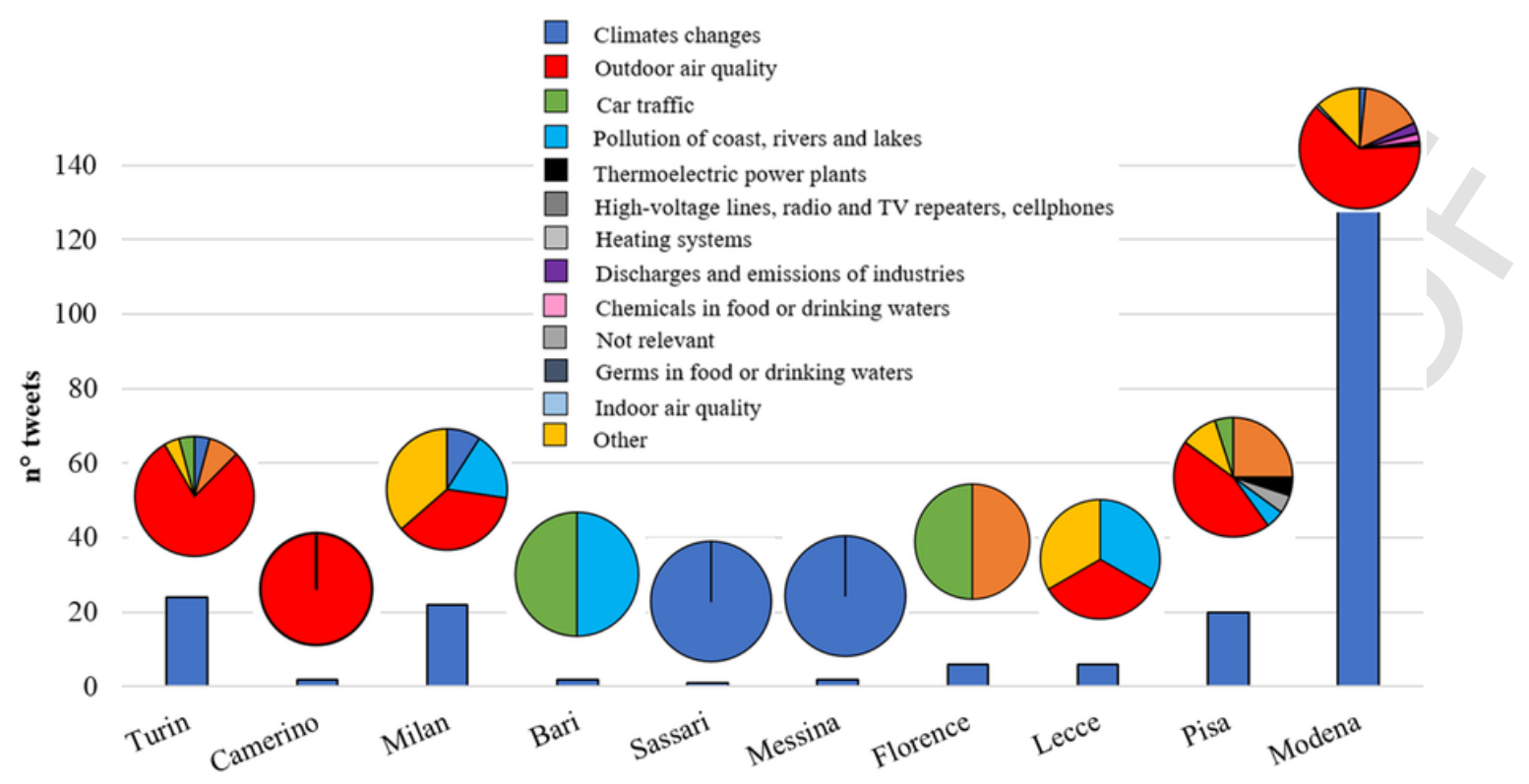

Fig. 4. Quantitative analysis of tweets for each city.

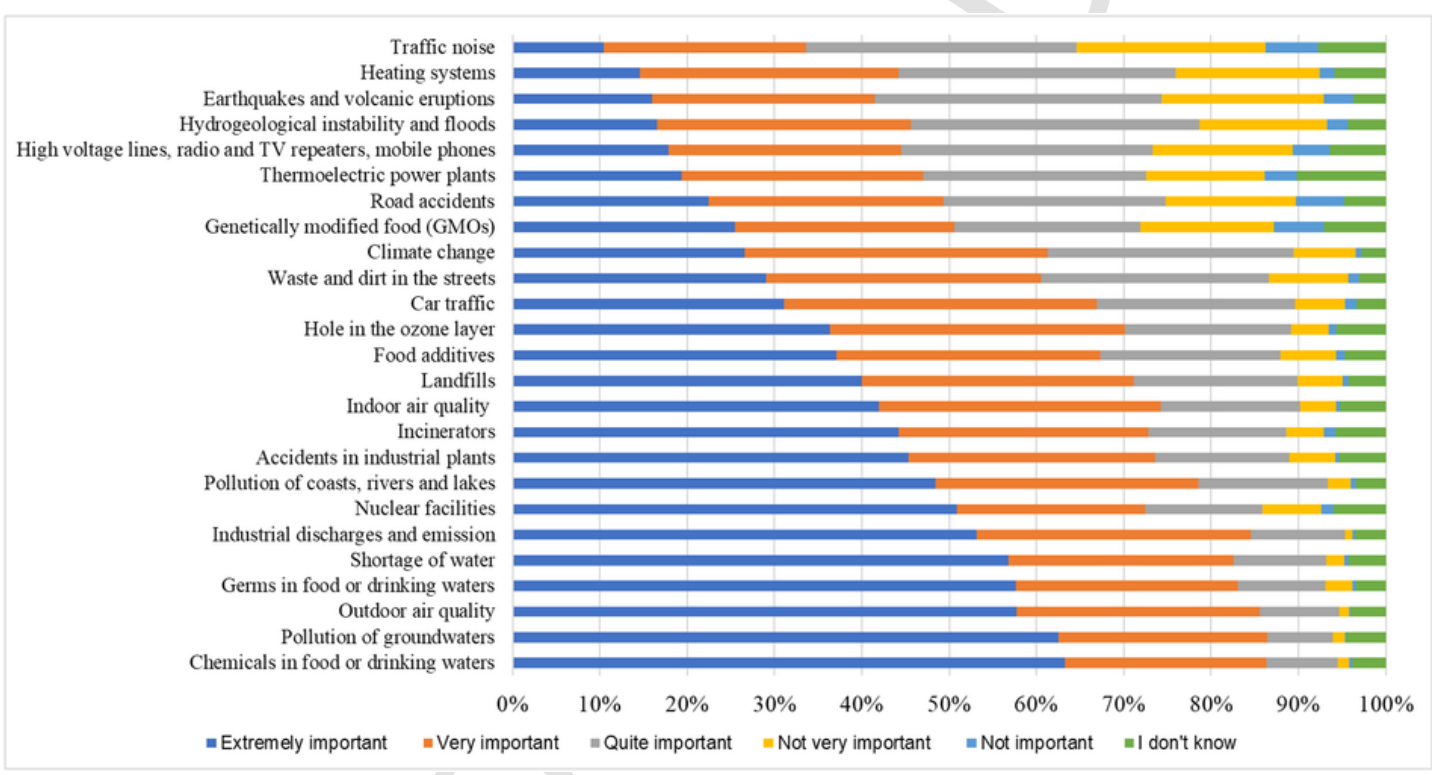

Fig. 5. Risk perception regarding environmental factors.

The global index of risk perception (calculated by summing the scores for the single risks), generally high (median 96, with a maximum of 125) was higher for students with functional health literacy $>9$ (functional health literacy $\leq 9$ vs functional health literacy $>9$, median: 95 vs 96), and those resident in Genoa, Turin, Sassari and Florence.

A general environmental health risk perception index was evaluated from the opinions on the pollution of water, air, soil and surrounding environments. This index was also positively associated with functional health literacy (functional health literacy $\leq 9$ vs functional health literacy $>9,95$ vs 96$)$.

The majority $(43.8 \%)$ of students reported that they were able to control the risks to their own health and considered their health to be quite good $(83.1 \%)$. These data were not influenced by functional health literacy, area of residence or gender.
Of the entire sample, $29.4 \%$ were smokers, with differences according to functional health literacy (functional health literacy $\leq 9$ vs functional health literacy $>9,33.1 \%$ vs $26.4 \%$ ) and (slightly) area of residence $(25.2 \%$ in the north, $30.4 \%$ in the centre, and $30.3 \%$ in the south and the islands).

Although the global risk perception index (high vs low) was not influenced by the smoking habits, differences were found between smokers and non-smokers in several questions of this section.

Regarding the importance of the environment as the cause of diseases, smokers considered it to be significantly stronger for tumors $(88.4 \%$ vs $86.9 \%)$ and heart diseases $(52.3 \%$ vs $51.5 \%)$, non-smokers for congenital malformation ( $59.7 \%$ vs $62.9 \%$ ), and neurological disorders (38.1\% vs $39.3 \%)$.

Among personal behaviors, students considered smoking as the most dangerous (89.9\% answered "very" or "extremely important"), 
followed by inadequate food preservation $(65.0 \%)$, misuse of chemicals for domestic purposes (house and garden) (63.1\%), exposure to solar radiation without any protection $(63.0 \%)$, and use of pellet stoves (27.4\%). Smoking seems to be related to a different risk perception of these behaviors: smokers only attributed more importance to pellet use for global warming $(27.6 \%$ of smokers answered "very" or "extremely important" vs $27.0 \%$ of non-smokers). On the other hand, non-smokers attributed more importance to smoke (non-smokers vs smokers: $90.9 \%$ vs $87.6 \%)$, solar UV exposure ( $65.0 \%$ vs $58.2 \%$ ), food preservation (66.0\% vs $62.4 \%)$ and misuse of chemicals $(64.7 \%$ vs $59.1 \%)$.

The global risk perception index was also lower for smokers (median 95 vs 96).

The multiple logistic regression showed that the global risk perception can be predicted by the use of internet and social media as sources of information (Table 1).

The number of tweets for all cities was not associated with the general risk perception index.

However, there was a clear difference in this index between Pisa and Modena (median 93.5 vs 95.5), possibly related to the number of tweets. The specific risk perception was lower in Pisa than in Modena regarding nuclear plants, emissions from heating systems, discharges and emissions from industries, electromagnetic fields (high voltage lines, radio, TV and cell phone repeaters) and genetically modified food. Only for the industry emissions and discharges, the number of tweets was different between the two cities (20 in Modena and 0 in Pisa).

Table 1

ORs and $95 \% \mathrm{CI}$ of risk perception determinants.

\begin{tabular}{|c|c|c|c|c|}
\hline Variables & $\begin{array}{l}\text { Low risk } \\
\text { perception } \\
\text { n (row \%) }\end{array}$ & $\begin{array}{l}\text { High risk } \\
\text { perception } \\
\mathrm{n}(\text { row \%) }\end{array}$ & $\begin{array}{l}\text { Crude OR } \\
(95 \% \mathrm{CI})\end{array}$ & $\begin{array}{l}\text { Adjusted } \mathrm{OR}^{\mathrm{a}} \\
(95 \% \mathrm{CI})\end{array}$ \\
\hline \multicolumn{5}{|c|}{ Internet and social as sources of information ${ }^{c}$} \\
\hline No & $149(14 \%)$ & $915(86 \%)$ & b & $\mathrm{b}$ \\
\hline Yes & $429(11.6 \%)$ & $\begin{array}{l}3281 \\
(88.4 \%)\end{array}$ & $\begin{array}{l}0.803 \\
(0.657-0.981)\end{array}$ & $\begin{array}{l}0.801 \\
(0.653-0.982)\end{array}$ \\
\hline \multicolumn{5}{|c|}{ Functional health literacy } \\
\hline High $(>9)$ & $296(11.1 \%)$ & $\begin{array}{l}2360 \\
(88.9 \%)\end{array}$ & $\mathrm{b}$ & $\mathrm{b}$ \\
\hline Low $(\leq 9)$ & $285(13.4 \%)$ & $\begin{array}{l}1837 \\
(86.6 \%)\end{array}$ & $\begin{array}{l}1.237 \\
(1.040-1.472)\end{array}$ & $\begin{array}{l}1.153 \\
(0.965-1.378)\end{array}$ \\
\hline \multicolumn{5}{|l|}{ Gender } \\
\hline Female & $381(12.3 \%)$ & $\begin{array}{l}2726 \\
(87.7 \%)\end{array}$ & b & \\
\hline Male & $200(12 \%)$ & $1468(88 \%)$ & $\begin{array}{l}0.975 \\
(0.812-1.70)\end{array}$ & $\begin{array}{l}0.988 \\
(0.820-1.190)\end{array}$ \\
\hline \multicolumn{5}{|c|}{ Area of residence } \\
\hline $\begin{array}{l}\text { North- } \\
\text { centre }\end{array}$ & $240(11.7 \%)$ & $\begin{array}{l}1809 \\
(88.3 \%)\end{array}$ & b & \\
\hline $\begin{array}{l}\text { South- } \\
\text { islands }\end{array}$ & $341(12.5 \%)$ & $\begin{array}{l}2388 \\
(87.5 \%)\end{array}$ & $\begin{array}{l}1.076 \\
(0.903-1.284)\end{array}$ & $\begin{array}{l}1.113 \\
(0.929-1.333)\end{array}$ \\
\hline \multicolumn{5}{|l|}{ Smoking } \\
\hline $\begin{array}{l}\text { Never } \\
\text { smoked }\end{array}$ & $380(11.5 \%)$ & $\begin{array}{l}2912 \\
(88.5 \%)\end{array}$ & & b \\
\hline $\begin{array}{l}\text { Current } \\
\text { smoker }\end{array}$ & $176(12.8 \%)$ & $\begin{array}{l}1194 \\
(87.2 \%)\end{array}$ & $\begin{array}{l}1.130 \\
(0.933-1.377)\end{array}$ & $\begin{array}{l}1.117 \\
(0.922-1.354)\end{array}$ \\
\hline
\end{tabular}

${ }^{\text {a }}$ Each odds ratio is adjusted for all other variables in the table.

b Reference category.

c Indicates important differences

\subsection{Trust}

In general students considered "institutional subjects" (Ministries of Health and Environment, Public Health and Regional Environmental Agencies, Municipalities, Regions and Physicians) to be more important than "non institutional" ones ("ecolabel" industries, Environmentalist Associations, Non-Governmental Organizations, local community stakeholders and individual citizens) in terms of the protection against environmental risks (mean: 3.7 vs 2.9 ).

Institutional subjects were considered more important for students with functional health literacy $>9$, for those who did not report the internet and social media as sources of information and for people from Genoa, Chieti, Pisa and Florence). On the other hand, students with functional health literacy $\leq 9$ and those resident in Florence, Padua and Sassari considered non-institutional subjects to be more important.

The real fulfillment of actions against environmental risks was in general considered more effective for institutional subjects (mean: 2.6 vs 2.4). Students with functional health literacy $>9$ were more trusting in the Ministry of Health and Public Health Agencies in terms of fulfillment, while students with functional health literacy $\leq 9$ were more trusting in Regional Environmental Agencies, Municipalities, "ecolabel" industries, environmental associations, non-governmental organizations, local community stakeholders, and individual citizens. Finally, females were more trusting in physicians than males.

The multiple logistic regression showed that trust in institutional subjects can be predicted by functional health literacy and area of residence (Table 2), while no predictive variables were found for trust in non-institutional subjects.

The responses to the trust in information on health risks from different sources, the importance of different subjects in protecting the general population from environmental health hazards, and the evaluation of their fulfillment are reported for single source/subject in Figs. B.1, B.2, B.3, respectively, of Supplemental Material B.

\subsection{Discussion and conclusion}

Environmental risk perception data have been studied for over 30 years, due to their importance in understanding people's attitudes and in planning information interventions (Covello, 2003). Nevertheless, our study shows various features that make it original and innovative: which mainly concern the large population considered, the functional health literacy analysis and the study of mass media and social media coverage.

The survey design (in a short period of time in every city), and the instrument (with a high internal consistency) made the answers comparable among the different geographical areas and the administration method (in study classrooms, with the immediate collection after completing) guaranteed a very high response rate (99\%) avoiding the selection bias based on the willingness to participate.

\subsection{Study population: socio-demographic characteristics and health literacy}

Studies on environmental health risk perception have often focused on specific groups of populations such as people living in polluted areas (Signorino and Beck, 2014; Coi et al., 2016; Kuroda, 2018), and high school or university students have also frequently been involved (Yapici et al., 2017; Durmuş-Özdemir and Şener, 2016; Weber et al., 2000; Bilgin et al., 2016; Young et al., 2015). 
Table 2

ORs and $95 \% \mathrm{CI}$ of trust in institutional subject determinants.

\begin{tabular}{|c|c|c|c|c|}
\hline Variables & $\begin{array}{l}\text { Low trust in } \\
\text { institutional } \\
\text { subjects } \\
\text { n (row \%) }\end{array}$ & $\begin{array}{l}\text { High trust in } \\
\text { institutional } \\
\text { subjects } \\
\text { n (row \%) }\end{array}$ & $\begin{array}{l}\text { Crude OR } \\
(95 \% \mathrm{CI})\end{array}$ & $\begin{array}{l}\text { Adjusted } \mathrm{OR}^{\mathrm{a}} \\
(95 \% \mathrm{CI})\end{array}$ \\
\hline \multicolumn{5}{|c|}{ Internet and social as sources of information } \\
\hline No & $270(25.4 \%)$ & $794(74.6 \%)$ & $\mathrm{b}$ & b \\
\hline Yes & $928(25 \%)$ & $2782(75 \%)$ & $\begin{array}{l}1.019 \\
(0.871-1.192)\end{array}$ & $\begin{array}{l}1.013 \\
(0.863-1.190)\end{array}$ \\
\hline \multicolumn{5}{|c|}{ Functional Health Literacy ${ }^{\mathrm{c}}$} \\
\hline High $(>9)$ & $606(22.8 \%)$ & $2050(77.2 \%)$ & $\mathrm{b}$ & $\mathrm{b}$ \\
\hline Low $(\leq 9)$ & $595(28 \%)$ & $1527(72 \%)$ & $\begin{array}{l}0.759 \\
(0.665-0.865)\end{array}$ & $\begin{array}{l}0.780 \\
(0.682-0.892)\end{array}$ \\
\hline \multicolumn{5}{|l|}{ Gender } \\
\hline Female & $800(25.7 \%)$ & $2307(74.3 \%)$ & $\mathrm{b}$ & b \\
\hline Male & $401(24 \%)$ & $1267(76 \%)$ & $\begin{array}{l}1.096 \\
(0.954-1.258)\end{array}$ & $\begin{array}{l}1.102 \\
(0.956-1.269)\end{array}$ \\
\hline \multicolumn{5}{|c|}{ Area of residence ${ }^{c}$} \\
\hline $\begin{array}{l}\text { North- } \\
\text { centre }\end{array}$ & $490(23.9 \%)$ & $1559(76.1 \%)$ & b & $\mathrm{b}$ \\
\hline $\begin{array}{l}\text { South- } \\
\text { islands }\end{array}$ & $711(26.1 \%)$ & $2018(73.9 \%)$ & $\begin{array}{l}0.892 \\
(0.781-1.019)\end{array}$ & $\begin{array}{l}0.870 \\
(0.759-0.996)\end{array}$ \\
\hline \multicolumn{5}{|l|}{ Smoking } \\
\hline $\begin{array}{l}\text { Never } \\
\text { smoked }\end{array}$ & $800(24.3 \%)$ & $2492(75.7 \%)$ & b & b \\
\hline $\begin{array}{l}\text { Current } \\
\text { smoker }\end{array}$ & $345(25.2 \%)$ & $1025(74.8 \%)$ & $\begin{array}{l}0.954 \\
(0.824-1.103)\end{array}$ & $\begin{array}{l}0.976 \\
(0.843-1.129)\end{array}$ \\
\hline
\end{tabular}

This is due to educational reasons and given that young people studying at a high level will likely be the future educators and decision makers. A detailed description of the surveys carried out among student populations is beyond the scope of the present study, however a literature review was performed in order to compare our study design and results with other studies, which is reported in Supplemental Material C. Briefly, in previous surveys among high school or university students, the questionnaires used have generally been based on multiple dimensions (i.e. demographic and social characteristics, awareness, attitudes and risk perception), and many risk factors have been considered. However, the aims, target populations and individual questions were different, so that our comparisons had to be limited to general aspects.

Studies considering such large populations and areas are very uncommon due to their complex organization. The majority of studies on students considered small numbers of people and limited geographical areas (see Table C.1), except for Weber et al. (2000), Altunoğlu and Atav (2016), and Young et al. (2015) who performed a nationwide survey enrolling numerous cities across the USA, Turkey and Taiwan, respectively.

Also, the survey carried out by Zhang and Fang (2013), Zhang et al. (2013) and Altunoğlu et al. (2017) included a large sample size, with $>1000$ students, but each study was limited to one city, thus lacking a broader vision of the whole country. Moreover, no one of these studies reached the size of our sample (4778 students).

Our study analyzed a very broad population, distributed over an entire country. This revealed spatial differences, but also increased the variability of the studied population, thus highlighting the most important associations or differences that go beyond the geographical distribution and can be generalized.

In addition, we carried out the study during the same time period (about a month) in all cities, so that differences among universities could be attributed mainly to local situations and characteristics of the sample (gender, area of residence, degree course).

Considering the functional health literacy, although in the case of environmental risks, some authors (Kuroda et al., 2018) measured health literacy in its critical and communicative dimensions, in this work we decided to use a simple measure of functional health literacy. The current Italian validated functional health literacy measurement tools (Lorini et al., 2017; Biasio et al., 2018) seem too long and time-consuming to be used as items in more complex questionnaires on risk awareness and perception. Moreover, our test is also easy to translate and does not need a cultural adaption, in the hypothesis of use in multicultural populations.

In the studied population no differences were found in functional health literacy according to gender and geographical areas, while it was positively associated with the level of university degree (it was higher for master's degrees). These results are partially in accordance with scientific literature, in which the level of health literacy increased with the grade of school education (Zhang et al., 2016; Dolezel et al., 2018). Moreover, further positive associations where found according to female gender and high family income (Vozikis et al., 2014; Zhang et al., 2016; Sukys et al., 2017).

\subsection{Sources of information and mass media and social media coverage}

As expected, the internet and social networks were the most used sources of information, in agreement with other surveys on similar populations (Bilgin et al., 2016; Durmuş-Özdemir and Şener, 2016; Zhang et al., 2013). This predominance was even more evident for the humanities students and for females, as reported in other studies (Escoffery et al., 2005; Fox, 2011; Rice, 2006; Horgan and Sweeney, 2012), although in the whole population and about health in general (EU, 2014) no difference were found by gender. Nevertheless, the quality of information was not completely satisfying for the $64 \%$ of students: this percentage was quite similar to the one resulting from Eurobarometer (EU, 2014), where $73 \%$ of general population was "fairly satisfied" of the health information on internet.

The risk perception of environmental problems is often socially mediated by the mass media, especially when it is not directly experienced (Weber et al., 2000). Mass media, including digital and social media have been proven to have a significant influence both on the knowledge and attitudes of people (Nelkin, 1987). Considering environmental risks, the information in the press, on TV, websites and social media have been strongly associated with risk perception and sometimes considered as a determinant of conflict (Bennett et al., 2010).

In the era of social networks, health-related information can be rapidly available, representing officially reported data with a good sensitivity. The social media information has recently been used for epidemiological surveillance, digital epidemiology (Khan et al., 2010; Salathe et al., 2012) and for environmental pollution research (geosocial search) (Carducci et al., 2017; Jang et al., 2015; Sammarco et al., 2017). Concerning geosocial search, it finds user activities advertised on Online Social Networks (OSNs), in a specific geographical area (Beckerman et al., 2008) and can be used to reveal alarming events and to follow how they are perceived over time. Despite the recognized high potential of infodemiology (the study of occurrence, distribution and content of electronic health information (Zeraatkar 
and Ahmadi, 2018)), there are some limitations in using it to gather epidemiological data: it tracks only the segment of population that uses the Web, that is often unevenly distributed; it allows only a surface picture of a situation without any other individual health information; and it does not allow to have precise information about the real size of the study population.

Our study had not an epidemiological aim, so it was planned without specific focus on a particular environmental risk or disease. It was a tentative approach to investigate if the level of risk perception directly evaluated by a questionnaire was related to measurable peaks of information, both on traditional mass media (newspapers) and social media (twitter). A further analysis of articles content in relations with health problems could be the aim of future development of this study.

\subsection{Environmental risk perception}

Globally, the impact of environmental risk on health was over-estimated by the majority of students in comparison with the global burden of diseases attributed to the environment by the WHO (Prüss-Üstün et al., 2016). The reasons of this discrepancy can be attributed to the lack of knowledge: in fact, a high functional health literacy was associated with a better estimation of the global burden of diseases attributed to the environment. Considering the importance of environment on specific health problems, the respiratory diseases were considered at the first place, followed by tumors, infectious diseases, congenital malformation, heart diseases and neurological disorders: the relative importance given to these diseases does not represent the one deriving from epidemiological studies at a global level (Prüss-Üstün, 2016).

To assess the perception of health risk deriving from the environment, a wide list of specific issues of possible concern for people was included in the questionnaire: these were chosen on the basis of previous studies (Carducci et al., 2017; Zhang and Fang, 2013) and with the aim of representing an overview of environmental health risks as broadly as possible. So it was quite predictable that the top three environmental risks were "chemicals in food or drinking waters", "pollution of groundwaters" and "outdoor air quality" that represent environmental matrices with the highest exposure by breathing or ingesting like ground waters that are frequently used for potable purposes and in the agri-food sector. Other environmental factors of growing concern such as climatic changes or contamination of sea, lakes and river water could have appeared less strictly related to health, even if they represent major environmental problems. Moreover, at least in the period of the survey, the information from mass media and social focused on the problems of air or water pollution rather than the climate change.

In general, the environmental risk perception is strongly related to the contingent situation and some surveys have been designed to explore the main risks based on the geographical area and the period. This is the case of surveys carried out in Turkey (Yapici et al., 2017) and Poland (Bilgin et al., 2016) where nuclear risks were ranked first among other risks, in coincidence with a public concern on this issue.

In our work, a wider list of environmental risk was investigated, also in order to evidence differences among cities. In fact, even if the risks mostly indicated as "very important" or "important" were related to chemical pollution of water and food everywhere, geographical differences were found for the perception of road accidents, genetically modified food, pollution of coasts, rivers and lakes. In Naples, the perception was lower for five risks (nuclear facilities, exhausts and emissions from industries, chemicals in food or drinking water, germs in food or drinking water and traffic noise). The differ- ent pattern of environmental health risks can be attributed to the environmental conditions of Naples, a city characterized by waste, air and noise pollution issues (Mazza et al., 2018), thus citizens tend to underestimate every-day-life risks as traffic noise or polluted air or waters.

The global risk perception index was generally quite high and higher in Genoa, Turin, Sassari and Florence. These differences may be attributed to the different environmental conditions, political debates, or media attention that changes over time and space.

Our study investigated the role of functional health literacy as a determinant of environmental health risk perception as already demonstrated for other topics: i.e. it was found to be positively associated for over-the-counter drugs (Calamusa et al., 2012), and diabetes (Darlow et al., 2012), and negatively for teratogenic agents during pregnancy (Lupattelli et al., 2017) and for vaccines (Brewer et al., 2007). In fact, the risk perception can be also affected by psychological and social factors and can show a reciprocal influence with trust (Siegrist et al., 2005). Both the "global risk perception" and the "general environmental health risk perception" indexes were higher for the high functional health literacy students, thus confirming the influence of this determinant.

On the contrary, the self-perception of their own health was not influenced either by functional health literacy, or area of residence, or gender: it was generally good $(83,1 \%)$ even higher than the one found in a nationwide survey on university students (77\%) (de Waure et al., 2015).

Lifestyles are often synergistic with environmental pollution as risk factors for many diseases: among them smoking habit is the most representative. In our sample about 30\% declared smoking, with a lower frequency for subjects with high health literacy and living in the North.

The obtained results are in accordance with Italian data on smoking habits (PASSI surveillance system, 2015-2018), with 28\% and 31\% of smokers in the 18-24 and 25-34 age groups, respectively, and the highest frequency in the regions of Centre and South. In similar populations the smoking habit was slightly higher among males (Teleman et al., 2016) while in our study no difference was found between genders.

The smoking habit influences the environmental health risk perception: many smokers consider the environment as cause of tumors and hearth diseases, that are, also, the most important diseases linked to smoke as reported in a recent report on smoking prevalence and attributable disease burden through the world (Reitsma et al., 2017). Accordingly, among personal behaviors, smokers tend to underestimate the importance of smoke as health hazard (EU, 2007). The majority of researches investigated the association between smoking status and risk perception of smoking (Ferrante et al., 2010; Wagener et al., 2014), but there is still a lack of studies addressing smoking and risk perception of environmental health issues. In our study, we observed a global risk perception index lower for smokers, suggesting that smokers are generally less afraid for factors that can affect their health: accordingly, several surveys on risky behaviors in young people demonstrated that dangerous lifestyles (smoke, drug addiction, gambling, etc.) are frequently associated (Rondina et al., 2007; Zuckerman and Kuhlman, 2000).

In our study, the internet and social media as sources of information were predictive for a higher risk perception. However, an analysis of the information from newspapers and tweets, there appeared to be no direct influence on risk perceptions, probably due to the scarcity of collected data during the period of survey.

The peak of tweets for Modena was difficult to explain in terms of their topics and the simultaneous newspapers articles. However, a 
further comparison between two cities (Modena and Pisa) showed a significant difference between the global risk perception index. Among the single risks, a higher risk perception corresponding to a higher number of tweets was found only for industry emissions and discharges.

\subsection{Trust}

Trust in institutions is considered an important factor against the "outrage". Some studies have demonstrated that in situations where an environmental problem occurs, it is very important a rapid response from institutions and the involvement of population (Sandman, 2003). Our study explored trust towards different subjects in informing correctly, in protecting general population from environmental health hazards and in really fulfilling their duties. On the whole, physicians were the most trusted for every of these aspects, confirming that they are still a reference about health, as demonstrated by numerous studies (Blendon and Benson, 2014). On the contrary, the second position was different according to the question: as information source, universities and research institution were more trusted than other public institutions. This result can derive from the study population represented by university students. Concerning the importance for the health protection from environmental risks, the second and third places were attributed to the involved Ministries (Health and Environment), but it is noteworthy the role assigned to individual citizens considered, "extremely important" or "very important" by the $57 \%$ of students. This indicates that the respondents give a high value to the action of general population, including themselves: some other surveys investigated this aspect, referring to the "locus of control" that indicates the degree to which people believe that they have control over their lives and events (Rotter, 1954). There are some evidences that a higher internal locus of control is associated to a greater predisposition to pro-environmental attitudes and behaviors (Pavalache-Ilie and Unianu, 2012; McCarty and Shrum, 2001). The frequency of people recognizing their own importance in protecting the environment was explored in other surveys: it was 37\% in 1990 in USA (Roper Organization, 1990), 28\% in a similar population $(\mathrm{GfK}, 2011)$ and $60 \%$ in an adult Italian population in 2016 (Carducci et al., 2017). On this question notable influences of sources of information, health literacy and area of residence were also detected. The lower use of internet and social as well as the higher health literacy seems to increase the importance attributed to institutional subjects.

The real fulfillment of actions against environmental risks was in general considered more effective for institutional subjects, mainly by students with functional health literacy $>9$.

The multiple logistic regression showed that trust in institutional subjects can be predicted by functional health literacy and area of residence. The functional health literacy was the only predictive factor for all the three aspects of trust in institutions: as sources of information, as important subjects and as effective actors against environmental health risks.

The main influence of the area of residence was on the trust in the real action of institutions, which was significantly higher in the centre-north, in agreement with the well-known Italian social-economical differences based on geographical pattern (Musolino, 2018).

\section{Conclusions}

The few studies that have evaluated the relationships between health literacy and risk perception in terms of environmental issues or trust (Kuroda et al., 2018) suggest that to plan effective risk communication strategies, the health literacy levels of target publics should be taken into account.

Our simple functional health literacy test may thus be useful in surveys on environmental health risk perception, attitudes and behaviors. It could be included in a more complex framework describing Environmental Health Literacy through related perspectives such as health literacy, risk communication, environmental health sciences, public health, and social sciences (Finn et al., 2017).

In our study, the functional health literacy measured with our simple test resulted associated with many of the investigated aspects: preferred sources of information and relative quality, risk perception for singular risks and on the whole, trust in institutions.

In conclusion, we believe that results of our study may be of help to strengthen information and education programs. In particular, functional health literacy should be increased by adding health information and education in school programs, to produce a basic knowledge for a better understanding of health and environmental issues. Moreover, the relevance of mass and social media suggests including them in planning communication intervention in environmental health and in verifying their results.

To the best of our knowledge this is the first study on environmental health risk perception and trust to show an association with functional health literacy, mass media and online social network. This highlights the need to include these factors in such surveys, together with the importance of analyzing social networks in order to provide a timely measurement of public sentiment ( $\mathrm{Wu}$ and $\mathrm{Li}, 2016$ ).

\section{Funding}

This research did not receive any specific grant from funding agencies in the public, commercial, or not-for-profit sectors.

\section{Uncited references}

Brown, 2014

Iizuka, 2000

Institute of Medicine, 2002

Jiang et al., 2015

Lundgren and McMakin, 1998

Lupattelli et al., 2014

Mazmanian and Morell, 1990

Mitchell and Dorling, 2003

PASSI surveillance system (Progressi delle Aziende Sanitarie per la Salute in Italia - Progress by local health units towards a healthier Italy), n.d

Rudd et al., 2003

\section{Declaration of Competing Interest}

None.

\section{Acknowledgements}

We wish to thank to English for Academics (e4ac.com) for editing and proofreading the manuscript. We thank the Italian Society of Public Health for supporting the activities of the Working Group of Health and Environment that promoted this work. 


\section{Appendix A. Supplementary data}

Supplementary data to this article can be found online at https:// doi.org/10.1016/j.scitotenv.2019.07.201.

\section{References}

Altunoğlu, B.D., Atav, E., 2016. Determining the environmental risk perceptions of secondary education students. Fresenius Environ. Bull. 25 (3), 671-683.

Aquino, F., Donzelli, G., De Franco, E., Privitera, Lopalco P.L., Carducci, A., 2017. The web and public confidence in MMR vaccination in Italy. Vaccine 35 (35), 4494-4498.

Beckerman, B., Jerrett, M., Brook, J.R., Verma, D.K., Arain, M.A., Finkelstein, M.M., 2008. Correlation of nitrogen dioxide with other traffic pollutants near a major expressway. Atmos. Environ. 42 (2), 275-290.

Bennett, P., Calman, K., Curtis, S., Fischbacher-Smith, D., 2010. Risk Communication and Public Health, 2nd ed. Oxford University Press, Oxford.

Berkman, N.D., Sheridan, S.L., Donahue, K.E., Halpern, D.J., Viera, A., Crotty, K., Holland, A., Brasure, M., Lohr, K.N., Harden, E., Tant, E., Wallace, I., Viswanathan, M., 2011. Health literacy interventions and outcomes: an updated systematic review. Evid. Rep. Technol. Assess. 199, 1-941.

Biasio, L.R., Lorini, C., Abbattista, G., Bozzola, E., De Castro, P., Della Seta, M., Villani, A., Bonaccorsi, G., 2018. Assessment of health literacy skills in family doctors' patients by two brief, self-administrated Italian measures. Ann. Ist. Super. Sanita 54 (3), 214-222.

Bilgin, A., Radziemska, M., Fronczyk, J., 2016. Determination of risk perceptions of university students and evaluating their environmental awareness in Poland Cumhuriyet University faculty of science. CSJ 37 (4).

Blendon, R.J., Benson, J.M., M.A., Hero, J.O., 2014. Public Trust in Physicians U.S. Medicine in International Perspective. N. Engl. J. Med.. 371:1570-1572.

Brewer, N.T., Chapman, G.B., Gibbons, F.X., Gerrard, M., McCaul, K.D., Weinstein, N.D., 2007. Meta-analysis of the relationship between risk perception and health behavior: the example of vaccination. Health Psychol. 26 (2), 36-145.

Brown, V.J., 2014. Risk perception: it's personal. Environ. Health Perspect. 122 (10), 276-279.

Calamusa, A., Di Marzio, A., Cristofani, R., Arrighetti, P., Santaniello, V., Alfani, S., Carducci, A., 2012. Factors that influence Italian consumers' understanding of over-the-counter medicines and risk perception. Patient Educ. Couns. 87 (3), (395-340).

Carducci, A., Donzelli, G., Cioni, L., Palomba, G., Verani, M., Mascagni, G., Anastasi, G., Pardini, R., Ceretti, E., Grassi, T., Carraro, E., Bonetta, S., Villarini, M., Gelatti, U., 2017. Air pollution: a study of citizen's attitudes and behaviors using different information sources. Epidemiol. Biostat. Public Health 14 (2) https://doi org/10.2427/12389.

Coi, A., Minichilli, F., Bustaffa, E., Carone, S., Santoro, M., Bianchi, F., Cori, L., 2016. Risk perception and access to environmental information in four areas in Italy affected by natural or anthropogenic pollution. Environ. Int. 95, 8-15.

Covello, V.T., 2003. Best practices in public health risk and crisis communication. J. Health Commun. 8 (1), 148-151.

Covello, V.T., Allen, F., 1998. Seven Cardinal Rules of Risk Communication. U.S. Environmental Protection Agency, Office of Policy Analysis, Washington D.C.

Darlow, S., Goodman, M.S., Stafford, J.D., Lachance, C.R., Kaphingst, K.A., 2012. Weight perceptions and perceived risk for diabetes and heart disease among overweight and obese women. Prev. Chronic Dis. 9 (81), 110-185.

de Waure, C., Soffiani, V., Virdis, A., Poscia, A., Di Pietro, M.L., 2015. Italian university students' self-perceived health and satisfaction of life. Ann. Ist. Super. Sanità 51 (2), 121-125. https://doi.org/10.4415/ANN_15_02_09.

Dettori, M., Arru, B., Azara, A., Piana, A., Mariotti, G., Camerada, M.V., Stefanelli, P., Rezza, G., Castiglia, P., 2018. In the digital era, is community outrage a feasible proxy indicator of emotional epidemiology? The case of meningococcal disease in Sardinia, Italy. Int. J. Environ. Res. Public Health 15 (7), 1512.

Dettori, M., Azara, A., Loria, E., Piana, A., Masia, M.D., Palmieri, A., Cossu, A., Castiglia, P., 2019. Population distrust of drinking water safety. Community outrage analysis, prediction and management. Int. J. Environ. Res. Public Health 16 (6)https://doi.org/10.3390/ijerph16061004, pii: E1004.

Dolezel, D., Shanmugam, R., Morrison, E.E., 2018. Are college students health literate? J. Am. Coll. Heal. 20, 1-8. https://doi.org/10.1080/07448481.2018.153900.

Durmuş-Özdemir, E., Şener, S., 2016. The impact of higher education on environmental risk perceptions. China-USA Business Rev. 15 (9), 459-471.

Escoffery, C., Miner, K.R., Adame, D.D., Butler, S., McCormick, L., Mendell, E., 2005. Internet use for health information among college students. J. Am. Coll. Heal. 53 (4), 183-188.

EU, 2007. Attitudes of Europeans Towards Tobacco. Special EUROBAROMETER 272c/Wave 66.2 - TNS Opinion \& Social. European Union (EU) Publication.
EU, 2014. European citizens' digital health literacy - Report. In: Flash Eurobarometer 404 - TNS Political \& Social. European Union (EU) Publication. ISBN: 978-92-79-43607-9https://doi.org/10.2759/86596.

Ferrante, M., Fiore, M., Leon, L., Constantidines, G., Castaing, M., Fallico, R., Sciacca, S., Modonutti, G.B., 2010. Age of smoking initiation, tobacco habits and risk perception among primary, middle and high school students in southern Italy. Italian J. Public Health 7 (3), 262-267.

Finn, S., O'Fallon, L., 2017. The emergence of environmental health literacy — from its roots to its future potential. Environ. Health Perspect. 125, 495-501.

Fox, S., 2011. The social life of health information 2011. Pew Internet and American Life Project 2011. Available at: www.pewinternet.org/reports/2011/Soical-LifeOf-Health- Information.aspx (last accessed 2 July 2019).

GfK Roper Consulting Green Gauge, 2011. The Environment: Public Attitudes and Individual Behavior - A Twenty-Year Evolution. Available at https://corp-uc1. azureedge.net//media/sc-johnson/our-purpose/social-responsibility/environment/ scjandgfkropergreengaugesflb.pdf, Accessed 2 July 2019.

Horgan, , Sweeney, J., 2012. University students' online habits and their use of the internet for health information. Comput. Inform. Nurs. 30 (8), 402-408. https://doi. org/10.1097/NXN.0b013e3182510703.

Iizuka, M., 2000. Role of Environmental Awareness in Achieving Sustainable Development. Prepared for the Project Enhancement of Citizen's Awareness in Formulation of Pollution. ECLAC (Economic Commission for Latin America and the Caribbean). Environment and Human Settlements Division of ECLAC, Santiago, Chile, $1-41$

Institute of Medicine, 2002. Speaking of Health: Assessing Health Communication Strategies for Diverse Populations. National Academy of Sciences. National Academy Press, Washington, DC.

Institute of Medicine, 2004. Health Literacy: A Prescription to End Confusion. National Academies Press, Washington, DC.

ISTAT, 2018. Demography in figures. ISTAT - Istituto Nazionale di StatisticaIn: http: //demo.istat.it/pop2018/index e.html, Accessed 4 February 2019.

Jiang, W., Wang, Y., Tsou, M.H., Fu, X., 2015. Using social media to detect outdoor air pollution and monitor air quality index (AQI): a geo-targeted spatiotemporal analysis framework with SinaWeibo (Chinese twitter). PLoS One 10 (10).

Kayser, L., Karnoe, A., Furstrand, D., Battheram, R., Christensen, K.B., Elsworth, G., Osborne, R., 2018. A multidimensional tool based on the ehealth literacy framework: development and initial validity testing of the ehealth literacy questionnaire (eHLQ). J. Med. Internet Res. 20 (2), 1-10.

Khan, A.S., Fleischauer, A., Casani, J., Groseclose, D.V.M., 2010. The next public health revolution: public health information fusion and social networks. Am. J. Public Health 100 (7), 1237-1242.

Kickbusch, I., Pelikan, J., Apfel, F., Agis, T., 2013. Health Literacy: The Solid Facts, 1st edn World Health Organisation Regional Office for Europe, Copenhagen.

Kuroda, Y., Iwasa, H., Orui, M., Moriyama, N., Nakayama, C., Yasumura, S., 2018. Association between health literacy and radiation anxiety among residents after a nuclear accident: comparison between evacuated and non-evacuated areas. Int. J. Environ. Res. Public Health 15 (7), 1463.

Lorini, C., Santomauro, F., Grozzini, M., Mantwill, S., Vettori, V., Lastrucci, V., Bechini, A., Boccolini, S., Bussotti, A., Bonaccorsi, G., 2017. Health literacy in Italy: a cross-sectional study protocol to assess the health literacy level in a population-based sample, and to validate health literacy measures in Italian language. BMJ Open 7 (11).

Lorini, C., Santomauro, F., Donzellini, M., Capecchi, L., Bechini, A., Bonanni, P., Bonaccorsi, G., 2018. Health literacy and vaccination: a systematic review. Hum. Vaccin. Immunother. 14 (2), 478-488.

Lundgren, R.E., McMakin, A.H., 1998. Risk communication. In: A Handbook for Communicating Environmental, Safety, and Health Risks, 5th edition Wiley-IEEE Press. ISBN: 978-1-118-45693-4.

Lupattelli, A., Picinardi, M., Einarson, A., Nordeng, H., 2014. Health literacy and its association with perception of teratogenic risks and health behavior during pregnancy. Patient Educ. Couns. 96 (2), 171-178.

Mazmanian, D., Morell, D., 1990. The 'NIMBY' syndrome: facility siting and the failure of democratic discourse. In: Vig, N.J., Kraft, M.E. (Eds.), Environmental Policy of the 1990s. CQ Press, Washington, D.C.

Mazza, A., Piscitelli, P., Falco, A., Santoro, M., Colangelo, M., Imbriani, G., Idolo, A., De Donno, A., Iannuzzi, L., Colao, A., 2018. Heavy environmental pressure in Campania and other Italian regions: a short review of available evidence. Int. J. Environ. Res. Public Health 15 (1)https://doi.org/10.3390/ijerph15010105, pii: E105.

McCarty, J.A., Shrum, L.J., 2001. The influence of individualism, collectivism, and locus of control on environmental beliefs and behaviour. J. Public Policy Mark. 20, 93-104.

Mitchell, G., Dorling, D., 2003. An environmental justice analysis of British air quality. Environ. Plan. A 35, 909-929.

Musolino, D., 2018. The north-south divide in Italy: reality or perception?. European spatial research and policy 25 (1), 29-53 https://doi.org/10.18778/1231-1952.25.1. 03 . 
Nelkin, D., 1987. Selling Science: How the Press Covers Science and Technology. W.H. Freeman, NewYork, NY.

Nutbeam, D., 2000. Health literacy as a public health goal: a challenge for contemporary health education and communication strategies into the 21 st century. Health Promot. Int. 15, 259-267.

Nutbeam, D., 2008. The evolving concept of health literacy. Soc. Sci. Med. 67 (12), 2072-2078.

PASSI surveillance system (Progressi delle Aziende Sanitarie per la Salute in Italia Progress by local health units towards a healthier Italy), Surveillance results for smoking habits 2015 - 2018. Available at: https://www.epicentro.iss.it/passi/dati/ fumoAccessed 2 July 2019.

Pavalache-Ilie, M., Unianu, E.C., 2012. Locus of control and the pro-environmental attitudes. Procedia - Social and Behavioral Sciences 33, 198-202.

Prüss-Üstün, Annette, Wolf, J., Corvalán, Carlos F., Bos, R. \& Neira, Maria Purificación. 2016. Preventing Disease Through Healthy Environments: A Global Assessment of the Burden of Disease From Environmental Risks. World Health Organization. https://apps.who.int/iris/handle/10665/204585

Ratzan, S.C., Parker, R.M., 2000. Introduction. In: Selden, C.R., Zorn, M., Ratzan, S.C., Parker, R.M. (Eds.), National Library of Medicine Current Bibliographies in Medicine: Health Literacy. National Institutes of Health, Bethesda, MD.

Reitsma, M.B., Fullman, N., Ng, M., Salama, J.S., Abajobir, A., Abate, K.H., Abbafati, C., et al., 2017. Smoking prevalence and attributable disease burden in 195 countries and territories, 1990-2015: a systematic analysis from the global burden of disease study 2015. Lancet 389 (10082), 1885-1906. https://doi.org/10.1016/ S0140-6736(17)30819-X).

Rice, R.E., 2006. Influences, usage, and outcomes of internet health information searching: multivariate results from the Pew surveys. Int. J. Med. Inform. 75 (1), $8-28$.

Rondina, Rde C., Gorayeb, R., Botelho, C., 2007. Psychological characteristics associated with tobacco smoking behaviour. J. Bras. Pneumol. 33 (5), 592-601.

Roper Organization, Johnson Wax, 1990. The Environment: Public Attitudes and Individual Behavior. The Roper Organization, Inc., 1990.

Rothman, K.J., Greenland, S., Lash, T.L., 2008. Modern Epidemiology. Published by Wolters Kluwer Health/Lippincott Williams \& Wilkins, Philadelphia USA. ISBN 9780781755641.

Rudd, R.E., Comings, J.P., Hyde, J.N., 2003. Leave no one behind: improving health and risk communication through attention to literacy. J. Health Commun. 8 (1), 104-115.

Salathe, M., Bengtsson, L., Bodnar, T.J., Brewer, D.D., Brownstein, J.S., Buckee, C., Campbell, E.M., Cattuto, C., Khandelwal, S., Mabry, P.L., 2012. Digital Epidemiology. PLoS Comput. Biol. 8 (7).

Sammarco, M., Tse, R., Pau, G., Marfia, G., 2017. Using geosocial search for urban air pollution monitoring. Pervasive Mob. Comput. 35, 15-31.

Sandman, P., 1987. Risk communication: facing public outrage. EPA J. 21-22.

Sandman, P., 2003. Responding to Community Outrage: Strategies for Effective Risk Communication. American Industrial Hygiene Association, Fairfax, Va.
Scheufele, D.A., 2014. Science communications as political communication. Proc. Natl. Acad. Sci. U. S. A. 16, 114

Signorino, G., Beck, E., 2014. Risk perception survey in two high-risk areas. In: Mudu, P. (Ed.), Human Health in Areas with Industrial Contamination. Terracini B, Martuzzi M. (WHO Regional Office for Europe, DK).

Smillie, L., Blissett, A., 2010. A model for developing risk communication strategy. J. Risk Res. 13 (1), 115-134.

Sukys, S., Cesnaitiene, V.J., Ossowsky, Z.M., 2017. Is health education at university associated with students' health literacy? Evidence from cross-sectional study applying HLS-EU-Q. Biomed. Res. Int. 2017, 8516843https://doi.org/10.1155/ $2017 / 8516843$

Teleman, A.A., Iodice, L., Poscia, A., de Waure, C., Ricciardi, W., Di Pietro, M.L., 2016. Female-male differences in health-related behaviours in the Italian university student population: perspectives from the "Sportello Salute Giovani" project. Ital. J. Gender-Spec. Med. 2 (1), (15-2).

Vozikis, A., Drivas, K., Milioris, K., 2014. Health literacy among university students in Greece: determinants and association with self-perceived health, health behaviours and health risks. Arch. Public Health 72 (1), 15. https://doi.org/10.1186/ 2049-3258-72-15, 23. (eCollection 2014).

Wasserstein, R.L., Lazar, N.A., 2016. The ASA's statement on p-values: context, process, and purpose. Am. Stat. 70 (2), 129-133.

Weber, J.M., Hair, J.F., Fowler, C.R., 2000. Developing a measure of perceived environmental risk. J. Environ. Educ. 32 (1), 28-35.

WHO, 2013. Health and Environment: Communicating the Risks. World Health Organization (WHO), Regional Office for Europe.

Wu, C.H., Li, T.Y., 2016. Social sensor: an analysis tool for social media. IJECS 7 (1), 77-94.

Yapici, G., Ögenler, O., Öner Kurt, A., Koças, F., Sasmaz, T., 2017. Assessment of environmental attitudes and risk perceptions among university students in Mersin, Turkey. J. Environ. Public Health 2017, 5650926.

Young, L.H., Kuo, H.W., Chiang, C.F., 2015. Environmental health risk perception of a nationwide sample of Taiwan college students majoring in engineering and health sciences. Hum. Ecol. Risk. Assess. 21 (2), 307-326.

Zeraatkar, K., Ahmadi, M., 2018. Trends of infodemiology studies: a scoping review. Health Inf. Libr. J. 35 (2), 91-120. https://doi.org/10.1111/hir.12216, (Epub 2018 May 4)

Zhang, L., He, G., Mol, A.P.J., Lu, Y.L., 2013. Public perceptions of environmental risk in China. J. Risk Res. 16 (2), 195-209.

Zhang, Y., Zhang, F., Hu, P., Huang, W., Lu, L., Bai, R., Sharma, M., Zhao, Y., 2016. Exploring health literacy in Medical University students of Chongqing, China: a cross-sectional study. PLoS One 11 (4), e0152547https://doi.org/10.1371/journal. pone.0152547. eCollection 2016.

Zuckerman, M., Kuhlman, D.M., 2000. Personality and risk-taking: common biosocial factors. J. Pers. 68 (6), 999-1029. 